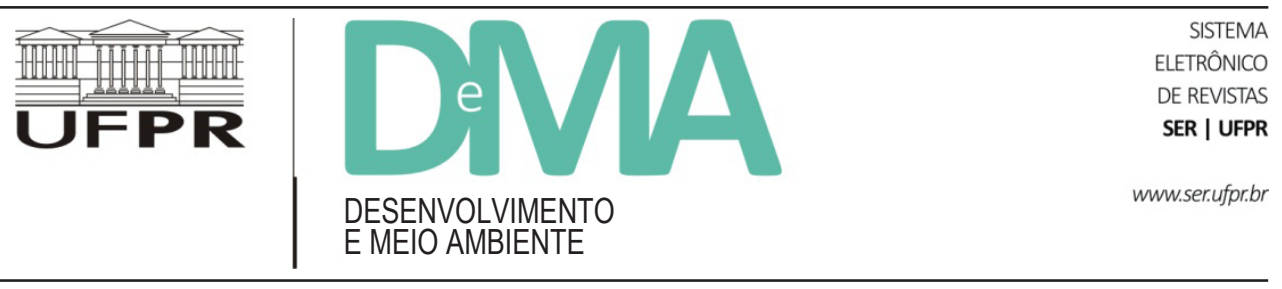

\title{
Aspectos normativos a respeito de resíduos de construção civil: uma pesquisa exploratória da situação no Brasil e em Portugal
}

\section{Regulatory Aspects Regarding Construction Waste: an Exploratory Research About the Situation in Brazil and in Portugal}

\author{
João Alexandre PASCHOALIN FILHO ${ }^{1}$, Antonio Jose Guerner DIAS ${ }^{2}$, Pedro Luis CORTES ${ }^{3}$ \\ ${ }^{1}$ Doutor em Engenharia Agrícola (UNICAMP). Professor do Programa de Mestrado em Gestão Ambiental da Universidade Nove de Julho \\ (UNINOVE). E-mail: jalexandre@uninove.br \\ ${ }_{2}^{2}$ Doutor em Geologia (Universidade do Porto). Professor da Faculdade de Ciências da Universidade do Porto (UP). E-mail: agdias@fc.up.pt \\ ${ }^{3}$ Doutor em Ciências da Comunicação (USP). Professor do Programa de Mestrado em Gestão Ambiental da Universidade Nove de Julho \\ (UNINOVE). Email: plcortes@uninove.br
}

Artigo: Recebido em: 23 de julho de 2013; Versão final aceita em: 28 de janeiro de 2014.

RESUMO A construção civil é um dos setores econômicos que primeiro responde a estímulos e condições favoráveis da economia de um país. Este ramo industrial também é um importante agente de desenvolvimento nacional, pois é responsável por grande parte do emprego gerado nacionalmente, além de ter um papel fundamental na redução do déficit habitacional e de infraestrutura. Contudo, esta indústria está também ligada à geração de grandes volumes de resíduos que, muitas vezes, são destinados de forma inadequada, causando impactos ao meio ambiente, tanto natural quanto urbano. A essa situação soma-se ainda a grande necessidade de utilização de matérias-primas naturais por parte deste setor produtivo, o que aumenta o impacto ambiental de suas atividades. Tanto no Brasil como em Portugal, o setor da construção civil se destaca promovendo benefícios econômicos e sociais. Entretanto, ambos os países enfrentam a mesma problemática em relação aos volumes de resíduos gerados, além da destinação e manejo realizados de forma inadequada. Este trabalho apresenta um estudo comparativo entre os aspectos normativos e legislações que regem a geração, o manejo e a gestão de resíduos de construção civil no Brasil e em Portugal, de forma a encontrar pontos em comum entre ambas as nações. Por meio das informações coletadas, verifica-se que ambos os países têm mecanismos legislativos e normativos com o objetivo comum de regular e fiscalizar a geração e a destinação dos resíduos de construção e demolição. Entretanto, ressalta-se que a discussão da problemática em torno dos resíduos de construção ainda carece de amadurecimento nos dois países.

Palavras-chave: resíduo de construção civil; sustentabilidade; aspectos normativos e legislativos. 
ABSTRACT The civil construction is one of the first economic sectors that respond to favorable economic conditions of a country. This sector is an important agent of national development providing employment rate increase and the housing and infrastructure deficit reduction. However, this industry may also be characterized by the large volumes of solid wastes it generates, which are often disposed on irregular sites, causing several environmental impacts. The situation is further aggravated by the great need to use natural raw materials, which increases the environmental impact of the activities of this highly productive sector of the economy. In Brazil, as in Portugal, the construction industry promotes economic and social benefits. However, both countries face the same problem in relation to the amounts of waste that is therefore generated. This paper presents an exploratory study conducted by means of literature and documental research with the aim of presenting the general situation in both countries and making comparisons between their normative aspects in order to broaden the discussion about the situation and to identify characteristics, concerns and situations which are common to both nations. Considering the information that has been gathered, it is possible to verify that in the two countries there are laws and regulations to enforce and control the generation and disposal of the construction and demolition waste. Nevertheless, it should be pointed out that the discussion about this kind of waste has yet to reach full maturity.

Keywords: civil construction wastes; sustainability; legislative and normative aspects.

\section{Introdução}

Nos centros urbanos, responsáveis por agregar a maior parte da população, são muitos os sinais dos impactos ao meio ambiente causados pelo homem. O ritmo imposto pelo crescimento econômico aos diversos setores da cadeia produtiva e o consumo, cada vez mais barato e intenso, têm causado a geração de grandes quantidades de Resíduos Sólidos Urbanos (RSU).

De uma forma geral, dentre os resíduos que compõem a massa de RSU gerada diariamente, grande parte é proveniente de atividades ligadas à construção civil. O crescimento deste setor é fortemente alavancado pelo panorama econômico e pela necessidade de atender o déficit habitacional e de infraestrutura. A construção civil também é responsável por uma considerável pegada ambiental, quer seja pela crescente demanda por matérias-primas naturais ou pela geração de resíduos. Ressalta-se que a construção civil, além de utilizar intensivamente os recursos naturais, gera uma quantidade considerável de resíduos durante a demolição de edifícios antigos, bem como durante a execução de novas obras.

Assim sendo, pode-se dizer que os Resíduos de Construção Civil (RCC) gerados pelo setor da construção têm merecido especial atenção de pesquisadores que buscam não apenas reduzir sua geração, mas também tornar possível a sua reutilização, reciclagem e manejo sustentável, buscando incrementar o valor agregado des- ses materiais. Além de reduzir a demanda por recursos naturais, a utilização de Resíduos de Construção Civil (RCC) em novas obras ajuda a resolver o problema da destinação desses materiais. Ressalta-se que uma considerável parte dos resíduos gerados por pequenas obras é, muitas vezes, depositada em áreas irregulares, e, mesmo as grandes obras, que em geral promovem a destinação de seus resíduos de forma correta, também têm dificuldades em encontrar áreas devidamente preparadas e legalizadas para receber estes resíduos.

Dessa forma, diante dos altos volumes de resíduos de construção produzidos diariamente e da necessidade de se reduzir o impacto do setor da construção civil, tanto no meio ambiente natural, quanto urbano, o Poder Público vem realizando ações no intuito de disciplinar a gestão dos resíduos de construção, responsabilizando e fiscalizando pequenos, médios e grandes geradores por meio de ações políticas e na elaboração de leis e resoluções, buscando contribuir para a criação de uma nova cadeia produtiva, transformando o resíduo em matéria-prima e gerando emprego e renda.

Portanto, pretende-se com esta pesquisa apresentar um estudo comparativo entre os aspectos normativos que regem a produção, o manejo e a gestão dos resíduos de construção civil no Brasil e em Portugal. Para tal, a metodologia deste trabalho consistiu na realização de uma pesquisa bibliográfica composta por artigos científicos, estudos técnicos, dados estatísticos e documentos 
legislativos referentes à situação da gestão e manejo de resíduos de construção e demolição no Brasil e em Portugal. As informações coletadas foram analisadas e sistematizadas no intuito de se possibilitar a organização destas e a discussão a respeito da temática em questão, identificando paradigmas presentes em ambos os países, tendências, contradições e pontos de comum acordo.

Ressalta-se que a escolha de Brasil e Portugal para a realização desta pesquisa bibliográfica é justificada, uma vez que nestes países a discussão a respeito do manejo e da gestão de resíduos de construção e demolição ainda encontra-se em processo de amadurecimento. Contou também na escolha destes países a proximidade histórica entre ambos, o que acarreta costumes, práticas e aspectos sociais semelhantes.

\section{Aspectos gerais da produção de resíduos de construção civil no Brasil e em Portugal}

O volume de resíduos gerados pode ser atribuído a quatro setores econômicos principais: agricultura, indústria, construção e serviços. Na Comunidade Europeia, em 2006, de acordo com Kloek e Blumenthal (2009), a indústria tradicional e a construção civil destacaram-se entre os setores que mais geraram resíduos, somando aproximadamente $83 \%$ de todo o volume produzido pelos setores produtivos em geral. O setor de serviços contabilizou cerca de $11 \%$ e a agricultura, $6 \%$. A construção civil é responsável por uma parte muito significativa dos resíduos gerados em Portugal, situação comum aos demais Estados Membros da União Europeia, onde se estima uma produção anual de 100 milhões de toneladas de resíduos de construção e demolição (Portugal, 2008a).

Em 2011, havia em Portugal, de acordo com o INE (Instituto Nacional de Estatística), aproximadamente 3,5 milhões de edifícios, sendo que cerca de 1,06 milhão havia sido construído no período compreendido entre 1991 e 2011 , ou seja, $30 \%$ do total de edifícios foram executados nas últimas duas décadas. Somente na capital, Lisboa, no período entre 2005 e 2012, foram protocolados cerca de 115.000 pedidos de licenciamento de obras e emitidos aproximadamente 32.300 alvarás.

No Brasil, no ano de 2010, de acordo com o Instituto Brasileiro de Geografia e Estatística (IBGE,
2011), o setor da construção civil foi responsável por um crescimento de $11,6 \%$ em seu Produto Interno Bruto (PIB) setorial, o melhor resultado dos últimos 24 anos, e pela geração de mais de 329 mil vagas formais no mercado de trabalho. Estima-se que este setor seja responsável pela geração de investimentos superiores a R \$ 90 bilhões por ano. A demanda por mão de obra também acompanha a necessidade de crescimento desta atividade, que é responsável pela geração de 62 empregos indiretos para cada 100 empregos diretos que são gerados (IBGE, 2011).

Entretanto, ao mesmo tempo em que a construção civil desempenha importante papel social, contribuindo diretamente na redução do déficit habitacional e de infraestrutura, indispensável ao progresso, este setor produtivo é também responsável por um consumo significativo de recursos naturais, uma vez que muitos dos insumos que entram na produção dos materiais de construção são obtidos pela extração em jazidas para atender à demanda de mercado. Estima-se no Brasil, de acordo com Dias (2004), que $50 \%$ dos recursos materiais extraídos da natureza estão relacionados à atividade de construção.

Além dos impactos causados pelo extrativismo, a construção civil também arca com o ônus de impor ao ambiente outras formas de agressão, tais como: poluição do ar e do solo, poluição sonora, geração de resíduos, etc. Embora nem sempre essa situação seja perceptível ao cidadão comum, as quantidades de resíduos de construção civil (RCC) geradas são significativas na composição dos Resíduos Sólidos Urbanos (RSU). Estima-se, por exemplo, que os RCC possam constituir cerca de $50 \%$ dos resíduos sólidos de algumas municipalidades brasileiras (Ulsen et al., 2010). Na cidade de Salvador, o volume de RCC constitui aproximadamente $45 \%$ do total gerado diariamente de RSU (Azevedo et al., 2006), enquanto que em São Paulo e Rio de Janeiro essa participação cai para $21 \%$ (Gomes et al., 2008). Na União Europeia, os RCC constituem cerca de $22 \%$ do volume total de RSU, conforme pode ser visto na Tabela 1, obtida em Barros e Jorge (2008).

Morais (2006) cita a relação no Brasil, de uma tonelada de lixo urbano recolhido para cada duas toneladas de resíduo de construção civil. O autor também apresenta dados relativos a algumas cidades brasileiras de médio e grande portes, nas quais a massa de RCC, em percentual, 
TABELA 1 - ORIGENS PRINCIPAIS DE RESÍDUOS NA UNIÃO EUROPEIA

\begin{tabular}{|l|c|}
\hline \multicolumn{1}{|c|}{ Tipo de Resíduo } & $\begin{array}{c}\text { Porcentagem } \\
\text { do total (\%) }\end{array}$ \\
\hline $\begin{array}{l}\text { Escórias da indústria mineira e } \\
\text { resultantes da explosão em pedreiras }\end{array}$ & 29 \\
\hline Indústrias & 26 \\
\hline Construção e demolição & 22 \\
\hline Urbanos & 14 \\
\hline Agrícolas, silvícolas e outros. & 9 \\
\hline
\end{tabular}

FONTE: Barros \& Jorge (2008)

varia entre $41 \%$ a $70 \%$ da massa total de resíduos sólidos urbanos. Em Portugal, a maior quantidade de resíduos de construção e demolição gerados, ou seja, aproximadamente $80 \%$, corresponde a materiais inertes, tais como: concreto, tijolos, ladrilhos, telhas, etc. Entre 10 e $20 \%$ da massa de RSU é composta por materiais, tais como: madeira, metais e produtos à base de gesso. Somente uma parcela ínfima pode ser caracterizada como metais, plásticos e produtos perigosos. No Brasil, a composição dos resíduos de construção e demolição foi apresentada em Carneiro (2005), a qual pode ser observada na Tabela 2, obtida para alguns municípios.

Em todas as cidades apresentadas na Tabela 2, verifica-se que os materiais cimentícios (concreto e argamassa) foram os que apresentaram maior participação na composição da massa de RCC. Dentre os municípios estudados, percebe-se que os municípios de Ribeirão Preto/SP e Salvador/BA têm 59 e 53\%, respectivamente, de concentração destes materiais na massa total de RCC gerada. Tal fato pode ser explicado, uma vez que os resíduos de materiais cimentícios são gerados tanto em obras de construção de novas edificações quanto na demolição e reforma de antigas. Por meio da Tabela 2 , pode-se notar também que solo e areia constituem a segunda maior parcela da massa de RCC. Isto ocorre em função da necessidade de escavação de fundações e obras de terraplenagem necessárias à execução de diversas obras.

John e Agopyan (2000) comentam que a quantidade de RCC gerada por habitante no Brasil varia entre 230 e $660 \mathrm{~kg} /$ habitante/ano. De acordo com dados da Associação Brasileira das Empresas de Limpeza Pública e Resíduos Especiais (ABRELPE, 2012), a quantidade per capita de resíduos de construção e demolição coletada, comparando-se os anos de 2010 e 2011, cresceu aproximadamente $7 \%$, ou seja, de $0,618 \mathrm{~kg} /$ habitante/dia para $0,656 \mathrm{~kg} /$ habitante $/$ dia. Este incremento correspondeu a uma massa adicional de $7.195 \mathrm{t} /$ dia recolhidas. Ainda, segundo a ABRELPE (2012), a região Centro-Oeste destacou-se como a que apresentou o maior índice de coleta de resíduos de construção e demolição per capita, aproximadamente $0,966 \mathrm{~kg} /$ habitante/dia. Dentre as regiões prospectadas, a região Norte apresentou o menor índice de coleta, ou seja, apenas $0,330 \mathrm{~kg} /$ habitante/dia.

No município de São Paulo, o mais populoso do Brasil, a Prefeitura Municipal contabilizou no ano de 2000, a partir dos dados obtidos por John e Agopyan (2000), aproximadamente $280 \mathrm{~kg} /$ habitante/ano. Schneider (2003) e Nunes (2004) contabilizaram nos anos de 2003 e 2004 cerca de 490 e $499 \mathrm{~kg} /$ habitante, respectivamente. Em Portugal, embora a produção de RCC seja inferior à média europeia, ela ainda é significativa. Há projeções que indicam que na década de 2020 a produção per capita em Portugal chegará ao redor de 400 kg/ano

TABELA 2 - COMPOSIÇÃO DO RCC PARA ALGUNS MUNICÍPIOS BRASILEIROS

\begin{tabular}{|c|c|c|c|c|}
\hline \multirow{2}{*}{ Material } & \multicolumn{4}{|c|}{ Localidade } \\
\cline { 2 - 5 } & São Paulo/SP & Ribeirão Preto/SP & Salvador/BA & Florianópolis/SC \\
\hline Concreto e argamassa & $33 \%$ & $59 \%$ & $53 \%$ & $37 \%$ \\
\hline Solo e areia & $32 \%$ & - & $22 \%$ & $15 \%$ \\
\hline Cerâmica & $30 \%$ & $23 \%$ & $14 \%$ & $12 \%$ \\
\hline Rochas & - & $18 \%$ & $5 \%$ & - \\
\hline Outros & $5 \%$ & - & $6 \%$ & $36 \%$ \\
\hline
\end{tabular}

FONTE: Carneiro (2005) 
(Coelho \& Brito, 2011). Em Lisboa, a quantidade de RCC foi calculada em 954 t/dia, o que resulta em uma produção per capita ao redor de $600 \mathrm{~kg} / \mathrm{ano}$ (Melo et al., 2011), acima da média portuguesa de $325 \mathrm{~kg} / \mathrm{ano}$ per capita (Pico, 2008).

\section{Aspectos normativos e legislativos em Portugal}

A União Europeia ainda não dispõe de legislação específica para os RCC, embora conte com algumas diretivas que fornecem uma orientação sobre a gestão de resíduos em geral (Mália et al., 2011). A primeira legislação europeia sobre resíduos em geral surgiu em 1975 (Diretiva 75/442/CEE), procurando garantir a eliminação de resíduos que representassem risco para a saúde humana ou para o meio ambiente, além de manifestar preocupação com os recursos naturais, ao incentivar a recuperação e reutilização de resíduos sólidos.

Na década de 1990, a União Europeia buscou a autossuficiência dos países membros quanto à eliminação de resíduos com a promulgação da Diretiva 91/156/CEE (Mália et al., 2011). Em 2008, foi publicada a Diretiva 2008/98/CE, que representou a mudança de uma política que se baseava na eliminação correta de resíduos para outra que passou a incentivar o seu reaproveitamento e sua reciclagem. Essa diretiva também incluiu metas de reciclagem de RCC na União Europeia (Mália et al., 2011).

Enquanto as diretivas europeias constituem um guia geral para os Estados Membros, há países que aprimoraram a sua legislação sobre RCC, constituindo-se em exemplos importantes, como é o caso da Dinamarca. Neste país, remonta à década de 1980 a primeira lei que discorre sobre o uso de RCC. Foi em 1985 que a Agência Dinamarquesa de Proteção Ambiental determinou que os resíduos de pavimentos de rodovias pudessem ser utilizados na construção de novas rodovias ou pavimentos, sem a necessidade de autorização. Por outro lado, caso se optasse pela deposição desses RCC em depósitos específicos, uma autorização seria necessária (Montecinos \& Holda, 2006). Isso indica que, desde a década de 1980, já estava em curso uma política para incentivar o reaproveitamento de RCC, tornando a sua simples deposição um procedimento mais trabalhoso, pelo menos do ponto de vista burocrático. $\mathrm{Na}$ década de 1990, a imposição de um imposto sobre resíduos não reciclados e a obrigatoriedade de separação de resíduos quando a quantidade gerada fosse superior a uma tonelada fizeram com que as quantidades recicladas declaradas atingissem a marca de $90 \%$. Uma legislação específica sobre a extração de agregados naturais também concorreu para que essa marca fosse atingida (Mália et al., 2011). O uso de RCC livres de contaminantes foi regulamentado em 1990, permitindo seu uso sem prévia autorização e sem o pagamento de uma taxação, que passou a ser aplicada aos resíduos a partir daquele ano (Montecinos \& Holda, 2006).

Em Portugal, o Decreto-Lei no 178/2006 estabeleceu o regime geral da gestão de resíduos, transpondo para a ordem jurídica interna a Diretiva $n^{\circ}$ 2006/12/CE, do Parlamento Europeu e do Conselho, de 5 de Abril, e a Diretiva 91/689/CEE, do Conselho, de 12 de Dezembro (Portugal, 2006b). Este Decreto-Lei aplica-se às operações de gestão de resíduos, compreendendo toda e qualquer operação de coleta, transporte, armazenagem, triagem, tratamento, valorização e eliminação de resíduos, bem como às operações de descontaminação de solos e ao monitoramento dos locais de deposição.

O Decreto-Lei no 178/2006 considera o resíduo de construção e demolição como sendo "o resíduo proveniente de obras de construção, reconstrução, ampliação, alteração, conservação e demolição e da derrocada de edificações". De acordo com este Decreto-Lei, os resíduos de construção e demolição são considerados inertes, sendo considerado perigoso o resíduo que apresente, pelo menos, uma característica que coloque em risco a saúde coletiva ou o ambiente, nomeadamente os identificados como tal na Lista Europeia de Resíduos (Portugal, 2006b, p. 6.530). Ainda neste Decreto-Lei, através do artigo $5^{\circ}$, referente ao "Princípio da Responsabilidade pela Gestão", é identificado como responsável pela destinação e deposição dos resíduos o próprio gerador, salvo se a produção diária de resíduos não exceder os 1.100 litros, situação em que é o próprio município que fica encarregado da sua gestão. O Decreto-Lei no 178/2006 também traz consigo o chamado "Princípio da Hierarquia das Operações de Gestão de Resíduos”, a qual estabelece os pontos a seguir transcritos: 
- A gestão de resíduos deve assegurar que à utilização de um bem sucede uma nova utilização ou que, não sendo viável a sua reutilização, se procede à sua reciclagem, ou ainda a outras formas de valorização;

- A eliminação definitiva de resíduos, nomeadamente, a sua deposição em aterro, constitui a última operação de gestão, justificando-se apenas quando seja técnica ou financeiramente inviável a prevenção, a reutilização, a reciclagem, ou outras formas de valorização;

- Os produtores de resíduos devem proceder à separação dos resíduos na origem, de forma a promover a sua valorização por fluxos e fileiras (Portugal, 2006b).

Dessa maneira, por meio do princípio apresentado, estabelece-se a seguinte hierarquia no manejo de resíduos de construção e demolição: $1^{\circ}$ - Prevenção ou redução; $2^{\circ}$ - Reutilização; $3^{\circ}$ - Reciclagem ou recuperação de materiais; $4^{\circ}$ - Recuperação de energia; $5^{\circ}$ - Deposição em aterro de forma segura e controlada.

Por meio da hierarquização apresentada, pode-se notar que a primeira opção, de acordo com o Decreto-Lei no 178/2006, em relação ao manejo dos resíduos de construção, se refere à redução de volumes e à prevenção de sua geração. A última opção se refere à deposição final dos resíduos em aterros próprios para o recebimento dos RCC. Barros \& Jorge (2008) comentam que o Decreto-Lei no ${ }^{\circ}$ 178/2006 veio destacar a importância dos resíduos de construção e demolição na problemática geral dos resíduos ao dar, pela primeira vez na legislação portuguesa, uma definição para os resíduos de construção e demolição.

Anteriormente, a classificação dos resíduos de construção e demolição era um tanto ambígua. Estes eram considerados como um dos fluxos de Resíduos Urbanos no Plano Estratégico de Resíduos Sólidos Urbanos (PERSU), como Resíduos Industriais (RI) pelo Plano Estratégico Setorial de Gestão de Resíduos Industriais (PESGRI) e até incluídos na categoria dos Resíduos Industriais Perigosos (RIP), devido à possibilidade de presença de componentes perigosos, tal como amianto (Segorbe, 2010). Em 2008, surgiu em Portugal uma legislação específica a respeito de resíduos de construção e demolição que complementou o Decreto-Lei $\mathrm{n}^{\circ}$ 178/2006, dada a importância do tema. A seguir, são destacados alguns artigos do Decreto-Lei no 46/2008 e seus respectivos conteúdos devido a sua importância na discussão a respeito da gestão e manejo de RCC:

Artigo $7^{\mathbf{0}}$ - A utilização de RCC em obra deve observar as normas técnicas nacionais e comunitárias aplicáveis e, na ausência destas, devem ser seguidas as especificações técnicas definidas pelo Laboratório Nacional de Engenharia Civil;

Artigo 10 - O novo Código da Contratação Pública exige, para as obras públicas, a elaboração de um plano de prevenção e gestão de RCC que acompanhe o projecto de execução, cujo cumprimento, demonstrado através de vistoria, é condição de recepção da obra;

Artigo 11 - Nas obras particulares, dispõe o Regime Jurídico de Urbanização e Edificação que o produtor está obrigado ao cumprimento do regime legal da gestão de RCC na execução das obras de urbanização ou nas obras de edificação;

Artigo 16 - O operador de gestão de RCC envia ao produtor, no prazo máximo de 30 dias, um certificado de recepção dos resíduos recebidos na sua instalação, devendo ser disponibilizada cópia do mesmo às autoridades de fiscalização, sempre que solicitado (Portugal, 2008b).

De acordo com Barros e Jorge (2008), a publicação do Decreto-Lei ${ }^{\circ}$ 46/2008, de 12 de março, teve como objetivo específico estabelecer o regime de gestão dos resíduos de construção e demolição. A seguir, a publicação da Portaria $n^{\circ}$ 417/2008, de 11 de junho, que estabeleceu os modelos de guias de acompanhamento de resíduos específicas para os resíduos de construção e demolição, veio dar um enquadramento legal mais claro a este tipo de resíduo e contribuir para uma aplicação mais eficaz da lei (Portugal, 2008a). Barros e Jorge (2008) citam o exemplo do item $\mathrm{n}^{\circ} 1$ do Artigo 10 do Decreto Lei $\mathrm{n}^{\circ}$ $46 / 2008$, que obriga que nas empreitadas e concessões de obras públicas o projeto e a execução destas sejam acompanhados de um plano de prevenção e gestão de resíduos de construção e demolição.

Em Portugal, a classificação dos resíduos é codificada de acordo com o apresentado pela Lista Europeia de Resíduos (LER), estabelecida de acordo com a Portaria número 209/2004 do dia 3 de março. Os resíduos de maior periculosidade apresentam o símbolo (*) ao seu lado. Os resíduos de construção e demolição, que constam no capítulo 17 da LER, são a seguir apresentados na Tabela 3. 
TABELA 3 - RESÍDUOS DE CONSTRUÇÃO E DEMOLIÇÃO (INCLUINDO SOLOS ESCAVADOS DOS LOCAIS CONTAMINADOS) E SUAS RESPECTIVAS CODIFICAÇÕES, CONFORME LISTA EUROPEIA DE RESÍDUOS (LER, 2004)

\begin{tabular}{|c|c|}
\hline \multicolumn{2}{|r|}{ Subitem: 1701 Betão (Concreto), tijolos, ladrilhos, telhas e materiais cerâmicos } \\
\hline 170103 & Ladrilhos, telhas e materiais cerâmicos \\
\hline 170107 & Misturas de betão, tijolos, ladrilhos, telhas e materiais cerâmicos não abrangidos em 170106 \\
\hline \multicolumn{2}{|r|}{ Subitem: 1702 Madeira, vidro e plástico } \\
\hline 170201 & Madeira \\
\hline 170203 & Plástico \\
\hline $170204(*)$ & Vidro, plástico e madeira contendo ou contaminados com substâncias perigosas \\
\hline \multicolumn{2}{|r|}{ Subitem: 1703 Misturas betuminosas, alcatrão e produtos de alcatrão } \\
\hline $170301(*)$ & Misturas betuminosas contendo alcatrão \\
\hline 170302 & Misturas betuminosas não abrangidas em 170301 \\
\hline $170303(*)$ & Alcatrão e produtos de alcatrão \\
\hline 170403 & Chumbo \\
\hline 170404 & Zinco \\
\hline 170405 & Ferro e aço \\
\hline 170406 & Estanho \\
\hline 170407 & Mistura de metais \\
\hline $170409(*)$ & Resíduos metálicos contaminados com substâncias perigosas \\
\hline $170410(*)$ & Cabos contendo hidrocarbonetos, alcatrão ou outras substâncias perigosas \\
\hline 170411 & Cabos não abrangidos em 170410 \\
\hline \multicolumn{2}{|r|}{ Subitem: 1705 Solos (incluindo solos escavados de locais contaminados), rochas e lamas de dragagem } \\
\hline $170503(*)$ & Solos e rochas contendo substâncias perigosas \\
\hline 170504 & Solos e rochas não abrangidos em 170503 \\
\hline $170605(*)$ & Materiais de construção contendo amianto \\
\hline \multicolumn{2}{|r|}{ Subitem: 1708 Materiais de construção à base de gesso } \\
\hline $170801(*)$ & Materiais de construção à base de gesso contaminados com substâncias perigosas \\
\hline 170802 & Materiais de construção à base de gesso não abrangidos em 170801 \\
\hline \multicolumn{2}{|c|}{ Subitem: 1709 Outros resíduos de construção e demolição } \\
\hline $170901(*)$ & Resíduos de construção e demolição contendo mercúrio \\
\hline $170902(*)$ & $\begin{array}{l}\text { Resíduos de construção e demolição contendo } \mathrm{PCB} \text { (por exemplo, vedantes com } \mathrm{PCB} \text {, revestimentos de piso à base de } \\
\text { resinas com } \mathrm{PCB} \text {, envidraçados contendo } \mathrm{PCB} \text {, condensadores com } \mathrm{PCB} \text { ) }\end{array}$ \\
\hline $170903(*)$ & Outros resíduos de construção e demolição (incluindo mistura de resíduos) contendo substâncias perigosas \\
\hline 170904 & Mistura de resíduos de construção e demolição não abrangidos em 1709 01, 170902 e 170903 \\
\hline
\end{tabular}

* Indica os resíduos de maior periculosidade.

FONTE: Lista Europeia de Resíduos (LER, 2004). 
Observando-se a Tabela 3, nota-se que a Lista Europeia de Resíduos (LER) não estabelece classificação dos resíduos de construção por meio de classes (como utilizado no Brasil), mas sim os separa em subitens que reúnem o material principal de constituição do resíduo. A periculosidade do resíduo é representada por meio da utilização de um asterisco ao lado na numeração do item que discrimina o resíduo.

\section{Aspectos normativos e legislativos no Brasil}

Até 2002, no Brasil não havia políticas públicas para os resíduos gerados pelo setor da construção civil. Na cidade de São Paulo, até aquele ano, a legislação municipal limitava-se apenas a proibir a deposição de RCC em vias e logradouros públicos, atribuindo ao gerador a responsabilidade pela sua remoção e destinação final (Schneider \& Phillip Jr., 2004). Contudo, com o passar do tempo, a problemática da geração e manejo dos RCC começou a se tornar mais evidente para a sociedade. Esta preocupação tem sido demonstrada através de seus governantes, que têm promulgado cada vez mais legislações sobre o tema da destinação dos resíduos de construção civil e demolição. Citam-se alguns exemplos:

- Estatuto das Cidades, Lei $n^{\circ} 10.257$ de 10 de junho de 2001 “... que determina novas e importantes diretrizes para o desenvolvimento sustentável dos aglomerados urbanos no país";

- Resolução no 307 de 5 de julho de 2002, do Conselho Nacional do Meio Ambiente (CONAMA), que definiu responsabilidades e criou deveres para o Gerenciamento dos Resíduos de Construção Civil;

- Lei n ${ }^{\circ} 11.445$, de 5 de janeiro de 2007, que "estabelece as diretrizes nacionais para o saneamento básico e para a Política Federal de Saneamento Básico";

- E a mais recente, que é a Política Nacional de Resíduos Sólidos, Lei $\mathrm{n}^{\mathrm{o}}$ 12.305, de 2 de agosto de 2010, que versa “... sobre as diretrizes relativas à gestão integrada e ao gerenciamento de resíduos sólidos, incluídos os perigosos, às responsabilidades dos geradores e do poder público e aos instrumentos econômicos aplicáveis".
O Conselho Nacional do Meio Ambiente (CONAMA), por meio da publicação da Resolução n ${ }^{\circ}$ 307/2002, trouxe a primeira resolução norteadora sobre os resíduos de construção e demolição no país. Esta Resolução vem ao longo do tempo sofrendo alterações por parte do Conselho, a fim de adequá-la à realidade da sociedade em geral. As resoluções que vieram para complementar esta primeira foram:

- Resolução no 348/2004: Incluiu o amianto na classe de resíduos perigosos;

- Resolução no 431/2011: Estabeleceu nova classificação para o gesso, considerando este como sendo de Classe B;

- Resolução n ${ }^{\circ} 448 / 2012$ : Alterou os artigos $2^{\circ}, 4^{\circ}$, $5^{\circ}, 6^{\circ}, 8^{\circ}, 9^{\circ}, 10$ e 11 da Resolução $n^{\circ} 307 / 2002$.

Pode-se dizer que a preocupação a respeito da problemática dos resíduos sólidos, distinguindo-se os de construção e demolição, é recente no Brasil, destacando-se a Resolução n 307/2002, do Conselho Nacional do Meio Ambiente, como um instrumento legal pioneiro que fixou prazos para as administrações municipais elaborarem e implantarem planos de gestão para os resíduos de construção e demolição. De acordo com a resolução CONAMA no ${ }^{\circ}$ 307, de 5 de julho de 2002, os resíduos de construção e demolição recebem a seguinte denominação:

Resíduos da construção civil: são os provenientes de construções, reformas, reparo de demolições de obras de construção civil, e os resultantes da preparação e da escavação de terrenos, tais como: tijolos, blocos cerâmicos, concreto em geral, solos, rochas, metais, resinas, colas, tintas, madeiras e compensados, forros, argamassa, gesso, telhas, pavimento asfáltico, vidros, plásticos, tubulações, fiação elétrica, etc., comumente chamados de entulhos de obras, caliça ou metralha (CONAMA, 2002).

Ainda segundo a resolução CONAMAn ${ }^{\circ}$ 307/2002, os resíduos de construção e demolição podem ser classificados em quatro grupos. Em 2004, em complementação à resolução CONAMA no $307 / 2002$, foi elaborada a resolução CONAMA nº 348/2004, na qual é incluído o amianto como pertencente à classe de resíduos perigosos. A Tabela 4 apresenta a classificação dos RCC (Resíduos 
de Construção Civil) de acordo com a resolução CONA$\mathrm{MA} \mathrm{n}^{\circ}$ 431/2011, que alterou a classificação apresentada na resolução CONAMA n ${ }^{\circ}$ 307/2002, alterando a classificação do Gesso de Classe C para Classe B.

Anteriormente à promulgação da Resolução CONAMA n 307/2002, o Brasil dispunha de uma Norma Brasileira denominada NBR 10.004 - "Resíduos Sólidos - Classificação", publicada pela Associação Brasileira de Normas Técnicas (ABNT) no ano de 1987, que servia de referência quanto à classificação dos resíduos sólidos. Após a entrada em vigor da Resolução CONAMA $n^{\circ}$ 307, a NBR 10.004 de 1987 sofreu uma revisão e foi publicada novamente no ano de 2004 com alterações, complementações e atualizações que vinham ao encontro das questões ambientais e o desenvolvimento sustentável em discussão desde a sua primeira publicação. De acordo com a NBR 10.004/2004, os resíduos de construção civil são classificados como inertes, ou seja, classe II-B, uma vez que estes não apresentam constituintes que, quando solubilizados, afetam os padrões de potabilidade da água. Além da NBR 10.004, a ABNT publicou as seguintes Normas Técnicas, específicas para resíduos de construção e demolição, relatadas na Tabela 5.
De uma forma geral, observando-se a Tabela 5, verifica-se que as Normas publicadas referem-se basicamente às atividades de triagem, destinação, reuso e reciclagem dos resíduos de construção e demolição, estabelecendo recomendações e padronizações técnicas. Posteriormente, no ano de 2010, a problemática dos resíduos de construção civil no Brasil também foi tratada na Política Nacional dos Resíduos Sólidos (PNRS), por meio da lei $\mathrm{n}^{\circ} 12.305 / 2010$. Esta política, dentre diversos aspectos, prevê redução na geração de resíduos, propondo a prática de hábitos de consumo sustentável e um conjunto de instrumentos para proporcionar o aumento da reciclagem e da reutilização dos resíduos sólidos e a destinação adequada dos rejeitos, além da necessidade de elaboração de planos de gestão de resíduos por agentes públicos e privados. Os planos previstos pela PNRS são a seguir listados:

1 - Plano Nacional de Resíduos Sólidos: sob a responsabilidade da União e coordenado pelo Ministério do Meio Ambiente;

2 - Plano Estadual de Resíduos Sólidos: sob a responsabilidade de cada Estado, sendo este requisito fundamental para a obtenção de recursos da União, ou

TABELA 4 - CLASSIFICAÇÃO DOS RCC (RESÍDUOS DE CONSTRUÇÃO CIVIL) DE ACORDO A RESOLUÇÃO CONAMANO $431 / 2011$

\begin{tabular}{|c|c|c|}
\hline Classe & Origem & Tipo de resíduo \\
\hline Classe A & $\begin{array}{l}\text { São os resíduos reutilizáveis ou } \\
\text { recicláveis como agregados. }\end{array}$ & $\begin{array}{c}\text { De pavimentação e de outras obras de infraestrutura, inclusive solos } \\
\text { provenientes de operações de terraplenagem. } \\
\text { Da construção, demolição reformas e reparos de edificações } \\
\text { (componentes cerâmicos, tijolos, blocos, telhas e placas de } \\
\text { revestimento, concreto e argamassa). }\end{array}$ \\
\hline Classe C & $\begin{array}{l}\text { Resíduos para os quais ainda não } \\
\text { foram desenvolvidas tecnologias } \\
\text { ou aplicações que permitam a sua } \\
\text { reciclagem ou recuperação. }\end{array}$ & Não especificado pela resolução. \\
\hline Classe D & $\begin{array}{l}\text { Resíduos perigosos oriundos de } \\
\text { processo de construção. }\end{array}$ & Tintas, solventes, óleos, amianto. \\
\hline
\end{tabular}

FONTE: Resolução CONAMA no 431/2011 
TABELA 5 - NORMAS TÉCNICAS DA ABNT (ASSOCIAÇÃO BRASILEIRA DE NORMAS TÉCNICAS) SOBRE RCC (RESÍDUOS DE CONSTRUÇÃO CIVIL) PUBLICADAS EM 2004

\begin{tabular}{|c|l|l|}
\hline Norma & \multicolumn{1}{|c|}{ Título } & \multicolumn{1}{|c|}{ Objetivo } \\
\hline NBR 15112 & $\begin{array}{l}\text { Resíduos da construção civil e resíduos volumo- } \\
\text { sos - Áreas de transbordo e triagem - Diretrizes } \\
\text { para projeto, implantação e operação. }\end{array}$ & $\begin{array}{l}\text { Esta Norma fixa os requisitos exigiveis para projeto, im- } \\
\text { plantação e operação de áreas de transbordo e triagem } \\
\text { de resíduos da construção civil e resíduos volumosos. }\end{array}$ \\
\hline NBR 15113 & $\begin{array}{l}\text { Resíduos sólidos da construção civil e resíduos } \\
\text { inertes - Aterros - Diretrizes para projeto, im- } \\
\text { plantação e operação. }\end{array}$ & $\begin{array}{l}\text { Esta Norma fixa os requisitos mínimos exigíveis para } \\
\text { projeto, implantação e operação de aterros de resíduos } \\
\text { sólidos da construção civil classe A e de resíduos inertes }\end{array}$ \\
\hline NBR 15114 & $\begin{array}{l}\text { Resíduos sólidos da construção civil - Áreas de } \\
\text { reciclagem - Diretrizes para projeto, implanta- } \\
\text { ção e operação. }\end{array}$ & $\begin{array}{l}\text { Esta Norma fixa os requisitos mínimos exigiveis para } \\
\text { projeto, implantação e operação de áreas de reciclagem } \\
\text { de resíduos sólidos da construção civil classe A. }\end{array}$ \\
\hline NBR 15115 & $\begin{array}{l}\text { Agregados reciclados de resíduos sólidos da } \\
\text { construção civil - Execução de camadas de pavi- } \\
\text { mentação - Procedimentos. }\end{array}$ & $\begin{array}{l}\text { Esta Norma estabelece os critérios para execuça de } \\
\text { camadas de reforço do subleito, sub-base e base de pa- } \\
\text { vimentos, bem como camada de revestimento primário, } \\
\text { com agregado reciclado de resíduo sólido da construção } \\
\text { civil, denominado agregado reciclado, em obras de pa- } \\
\text { vimentação. }\end{array}$ \\
\hline NBR 15116 & $\begin{array}{l}\text { Agregados reciclados de resíduos sólidos da } \\
\text { construção civil - Utilização em pavimentação e } \\
\text { preparo de concreto sem função estrutural - Re- } \\
\text { quisitos. }\end{array}$ & $\begin{array}{l}\text { Esta Norma estabelece os requisitos para o emprego de } \\
\text { agregados reciclados de resíduos sólidos da construção } \\
\text { civil. }\end{array}$ \\
\hline
\end{tabular}

FONTE: ABNT (2004)

por ela controlados, a serem destinados aos empreendimentos e serviços destinados ao gerenciamento de resíduos sólidos;

3 - Plano Municipal de Gestão Integrada de Resíduos Sólidos: sob a responsabilidade das municipalidades, sendo este requisito fundamental para captação de recursos junto à União que serão destinados a empreendimentos e serviços relacionados à limpeza urbana e ao manejo de resíduos sólidos;

4 - Plano de Gerenciamento de Resíduos Sólidos: estão sujeitos à elaboração deste plano os geradores de resíduos (perigosos ou não) de uma maneira geral, entre estes, as empresas de construção civil.

\section{Aspectos semelhantes entre Brasil e Portugal}

Nas Tabelas 6 e 7 são listados e sintetizados os principais documentos legislativos e normativos que incidem sobre os resíduos de construção e demolição aprovados no Brasil e em Portugal.
Deve ser destacado, por meio da observação das Tabelas apresentadas, que Portugal e Brasil possuem alguns pontos coincidentes a respeito da problemática dos resíduos de construção e demolição quando comparados o Decreto-Lei ${ }^{\circ}$ 46/2008 e a resolução CONAMA $\mathrm{n}^{\circ} 307 / 2002$, ou seja, ambos os documentos consideram que os geradores deverão ser os responsáveis pelos resíduos produzidos a partir de suas atividades. A resolução CONAMA n 307/2002 cita:

[...] os geradores de resíduos da construção devem ser responsáveis pelos resíduos das atividades de construção, reforma, reparos e demolições de estruturas e estradas, bem como por aqueles resultantes da remoção de vegetação e escavação de solos [...] (CONAMA, 2002).

O Decreto-Lei $\mathrm{n}^{\circ} 46 / 2008$ traz o seguinte em seu Capítulo 1 , artigo $3^{\circ}$, parágrafo 1 :

A gestão dos RCC é da responsabilidade de todos os intervenientes no seu ciclo de vida, desde o produto 
TABELA 6 - PRINCIPAIS DOCUMENTOS LEGISLATIVOS QUE PODEM INCIDIR SOBRE OS RESÍDUOS DE CONSTRUÇÃO E DEMOLIÇÃO APROVADOS NO BRASIL ENTRE 1987 E 2012

\begin{tabular}{|c|c|}
\hline Legislação & Descrição geral \\
\hline $\begin{array}{l}\text { Norma Técnica ABNT: NBR 10.004/1987 (cancelada). Substituída } \\
\text { pela NBR 10.004/2004 (ABNT, 2004) }\end{array}$ & $\begin{array}{l}\text { Classifica os resíduos sólidos quanto aos seus riscos potenciais ao meio } \\
\text { ambiente e à saúde pública para que estes resíduos tenham manejo e } \\
\text { destinação adequados. }\end{array}$ \\
\hline $\begin{array}{l}\text { Normas Técnicas ABNT: NBR } 15112 \text { até 115116/2004 (ABNT, } \\
\text { 2004). }\end{array}$ & $\begin{array}{l}\text { Apresenta recomendações técnicas para o manejo, destinação e recicla- } \\
\text { gem de resíduos de construção civil }\end{array}$ \\
\hline $\begin{array}{l}\text { Lei } \mathrm{n}^{\mathrm{o}} 15.445 / 2007 \text { - Política Nacional de Saneamento Básico } \\
\text { (BRASIL, 2007). }\end{array}$ & $\begin{array}{l}\text { Estabelece diretrizes nacionais para o saneamento básico; altera as Leis } \\
\text { nos } 6.766 \text {, de } 19 \text { de dezembro de } 1979,8.036 \text {, de } 11 \text { de maio de } 1990, \\
\text { 8.666, de } 21 \text { de junho de } 1993,8.987 \text {, de } 13 \text { de fevereiro de } 1995 \text {; revoga } \\
\text { a Lei no } 6.528 \text {, de } 11 \text { de maio de } 1978 \text {; e dá outras providências }\end{array}$ \\
\hline Resolução CONAMA nº 448/2012 (CONAMA, 2012). & $\begin{array}{l}\text { Altera os artigos. } 2^{\circ}, 4^{\circ}, 5^{\circ}, 6^{\circ}, 8^{\circ}, 9^{\circ}, 10 \text { e } 11 \text { da Resolução n }{ }^{\circ} 307 \text {, de } 5 \\
\text { de julho de } 2002 \text {, do Conselho Nacional do Meio-Ambiente- CONAMA }\end{array}$ \\
\hline
\end{tabular}

FONTE: Os Autores

TABELA 7 - PRINCIPAIS DOCUMENTOS LEGISLATIVOS QUE PODEM INCIDIR SOBRE OS RESÍDUOS DE CONSTRUÇÃO E DEMOLIÇÃO APROVADOS EM PORTUGAL ENTRE 1996 E 2009

\begin{tabular}{|c|c|}
\hline Legislação & Descrição geral \\
\hline Portaria no 335/97, 16 de maio de 1997 (Portugal, 1997c). & Estabelece as regras de transporte de resíduos \\
\hline Decreto Lei $\mathrm{n}^{\circ}$ 239/97, 9 de setembro de 1997 (Portugal, 1997a). & $\begin{array}{l}\text { Estabelece as regras gerais de gestão de resíduos (revogada pelo De- } \\
\text { creto Lei } \mathrm{n}^{\circ} 178 / 2006 \text { ) }\end{array}$ \\
\hline Portaria ${ }^{\circ}$ 961/98, 10 de novembro de 1998 (Portugal, 1998a). & $\begin{array}{l}\text { Legisla a autorização de processos de gestão de resíduos industriais, } \\
\text { urbanos e de outros tipos (revogada pelo Decreto Lei }{ }^{\circ}{ }^{\circ} \text { 178/2006) }\end{array}$ \\
\hline Decreto Lei n ${ }^{\circ}$ 516/99, 2 de agosto de 1999 (Portugal, 1999b). & $\begin{array}{l}\text { Aprova o Plano Estratégico para os resíduos industriais não peri- } \\
\text { gosos }\end{array}$ \\
\hline Portaria $\mathrm{n}^{\circ} 321 / 99,11$ de agosto de 1999 (Portugal, 1999a). & $\begin{array}{l}\text { Regula a instalação e a gestão de aterros de materiais não perigosos } \\
\text { (revogada pelo Decreto Lei } n^{\circ} 152 / 2002 \text { ) }\end{array}$ \\
\hline 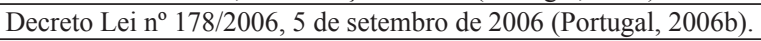 & Estabelece as regras gerais de gestão de resíduos \\
\hline Portaria n $^{\circ}$ 1408/2006, 18 de dezembro de 2006 (Portugal, 2006a). & $\begin{array}{l}\text { Aprova o regulamento de funcionamento do Sistema Integrado de } \\
\text { Registro Eletrônico de Resíduos (SIRER) }\end{array}$ \\
\hline Decreto Lei n ${ }^{\circ} 46 / 2008,12$ de março de 2008 (Portugal, 2008b). & Estabelece as regras gerais de gestão de RCC \\
\hline Decreto Lei $n^{\circ}$ 183/2009, 10 de agosto de 2009 (Portugal, 2009). & Regime jurídico da deposição de resíduos em aterros \\
\hline
\end{tabular}

FONTE: Os Autores 
original até o resíduo produzido, na medida da respectiva intervenção do mesmo, nos termos do disposto presente decreto-lei (Portugal, 2008b).

Outro ponto de intersecção entre ambos os documentos consiste no fato de que estes estimulam prioritariamente a não geração (ou minimização) dos resíduos de construção como ferramenta fundamental de manejo. A resolução CONAMA n ${ }^{\circ}$ 307/2002 no artigo $4^{\circ}$ relata:

Os geradores deverão ter como objetivo prioritário a não geração de resíduos e, secundariamente, a redução, a reutilização, a reciclagem e a destinação final (CONAMA, 2002).

Da mesma forma, o Decreto-Lei n ${ }^{\circ} 46 / 2008$, artigo $5^{\circ}$ do Capítulo II, prevê a minimização da produção dos resíduos, a adoção de formas de valorização destes e a adoção de métodos construtivos que facilitem a demo- lição orientada na gestão de resíduos. Pode-se também salientar que tanto Portugal quanto o Brasil têm documentos legislativos que tratam as questões dos resíduos de construção civil de maneira menos específica, ou seja, incluindo estes no grupo de resíduos sólidos de uma forma geral, tal como pode ser observado na Lei $\mathrm{n}^{\mathrm{o}} 12.305 / 2010$, que instituiu a Política Nacional de Resíduos Sólidos (PNRS) brasileira, e o Decreto-Lei $n^{\circ} 178 / 2006$ português. Contudo, deve-se destacar que ambos os países também publicaram decretos e resoluções que tratam de forma mais específica a questão dos resíduos de construção e demolição, tais como a resolução CONAMA n 307/2002 e o Decreto-Lei no 46/2008.

Também se verifica que Brasil e Portugal são bastante enfáticos na responsabilização do gerador a respeito da necessidade da elaboração de planos de gestão dos resíduos produzidos, os quais deverão dar prioridade à prevenção e redução da geração dos resíduos, e, por último, o descarte, desde que efetuado em locais apropriados e de maneira correta. A Tabela 8 apresenta aspectos

TABELA 8 - ASPECTOS SEMELHANTES ENTRE A RESOLUÇÃO CONAMA No 307/2002 (CONAMA, 2002) E O DECRETO-LEI Nº 46/2008 (PORTUGAL, 2008B)

\begin{tabular}{|l|c|c|l|}
\hline \multicolumn{1}{|c|}{ Assunto } & $\begin{array}{c}\text { CONAMA } \\
\mathbf{n}^{\mathbf{0}} \mathbf{3 0 7 / 2 0 0 2}\end{array}$ & $\begin{array}{c}\text { Decreto-Lei } \\
\mathbf{n}^{\mathbf{0}} \mathbf{4 6 / 2 0 0 8}\end{array}$ & \multicolumn{1}{|c|}{ Considerações } \\
\hline $\begin{array}{l}\text { Estabelecimento de critérios, pro- } \\
\text { cedimentos, regimes de operações } \\
\text { e disciplinamento de ações }\end{array}$ & Artigo $1^{\circ}$ & Artigo $1^{\circ}$ & $\begin{array}{l}\text { Os documentos apresentam nestes artigos seus res- } \\
\text { pectivos objetivos }\end{array}$ \\
\hline $\begin{array}{l}\text { Estabelecimento de hierarquia de } \\
\text { ações na gestão dos resíduos de } \\
\text { construção e demolição }\end{array}$ & Artigo $4^{\circ}$ & Artigo $2^{\circ}$ & $\begin{array}{l}\text { Ambos os documentos estabelecem a preferência } \\
\text { pela não geração de resíduos e secundariamente a } \\
\text { redução, reuso e destinação destes. }\end{array}$ \\
\hline $\begin{array}{l}\text { Responsabilização dos geradores } \\
\text { de resíduos de construção e demo- } \\
\text { lição }\end{array}$ & Artigo $5^{\circ}$ & Artigo $3^{\circ}$ & $\begin{array}{l}\text { Estabelece as competências e responsabilidades } \\
\text { em relação aos geradores de resíduos de constru- } \\
\text { ção, tanto na esfera pública quanto na privada }\end{array}$ \\
\hline $\begin{array}{l}\text { Elaboração de planos específicos } \\
\text { para gestão de resíduos de constru- } \\
\text { ção e demolição }\end{array}$ & Artigos $5^{\circ}, 6^{\circ}, 7^{\circ}$ & Artigo $4^{\circ}$ & $\begin{array}{l}\text { Estabelece as responsabilidades em relação à ela- } \\
\text { boração de planos de gerenciamento de resíduos } \\
\text { de construção e demolição tanto na esfera pública } \\
\text { como na privada }\end{array}$ \\
\hline $\begin{array}{l}\text { Destinação de resíduos dos resídu- } \\
\text { os de construção e demolição }\end{array}$ & Artigo $10^{\circ}$ & Artigos $6^{\circ}, 7^{\circ}$, \\
$8^{\circ}$, e $9^{\circ}$ & $\begin{array}{l}\text { Apresenta formas de destinação de resíduos de } \\
\text { construção tais como: reuso, reciclagem, deposi- } \\
\text { ção em aterros e formas de transporte }\end{array}$ \\
\hline $\begin{array}{l}\text { Orientações para elaboração de } \\
\text { projetos de gerenciamento de resí- } \\
\text { duos de construção e demolição }\end{array}$ & Artigo $9^{\circ}$ & Artigo $10^{\circ}$ e \\
$11^{\circ}$ & $\begin{array}{l}\text { Orienta para a necessidade de elaboração de planos } \\
\text { de gestão e gerenciamento de resíduos de constru- } \\
\text { ção, estabelecendo procedimentos e responsabili- } \\
\text { dades }\end{array}$ \\
\hline
\end{tabular}

FONTE: Os Autores 
semelhantes observados entre a resolução CONAMA no 307/2002 e o Decreto-Lei no 46/2008.

Um aspecto a ser destacado, comparando-se os documentos apresentados na Tabela 8, consiste no fato de que o Decreto-Lei no 46/2008 apresenta uma série de artigos e parágrafos que instituem mecanismos específicos para fiscalização, taxação e demais ações a serem tomadas pelo poder público. Em contrapartida, a resolução CONAMA n ${ }^{\circ} 307 / 2012$, por meio dos artigos $5^{\circ}$ e $6^{\circ}$, estabelece diretrizes mais gerais ao poder público, deixando os Municípios autônomos para a elaboração e implantação de seus Planos Integrados de Gerenciamento de Resíduos de Construção, desde que sejam observadas as diretrizes relatadas na resolução. Outro aspecto, no qual diferem os documentos analisados, é que a resolução CONAMA no 307/2002 (e depois suas alterações) traz consigo a classificação dos resíduos de construção e demolição em classes A, B, C e D. O Decreto-Lei n ${ }^{\circ}$ 46/2008 não estabelece classificações entre os resíduos de construção e demolição, uma vez que em Portugal é utilizada a Lista Europeia de Resíduos (LER), implantada desde 2004 e resultante do Catálogo Europeu

\section{Referências}

ABNT - Associação Brasileira de Normas Técnicas. NBR 15112: Diretrizes para projeto, implantação e operação de áreas de triagem e transbordo. Rio de Janeiro, 2004.

: NBR 15113: Diretrizes para projeto, implantação e operação de aterros. Rio de Janeiro, 2004.

: NBR 15114: Diretrizes para projeto, implantação e operação de áreas de reciclagem. Rio de Janeiro, 2004.

: NBR 15115: Procedimentos para execução de pavimentação utilizando agregados reciclados de resíduos da construção. Rio de Janeiro, 2004.

: NBR 15116: Requisitos para a utilização em pavimentos e preparo de concreto sem função estrutural com agregados reciclados de resíduos da construção. Rio de Janeiro, 2004.

: NBR 10004: Resíduos sólidos - Classificação. Rio de Janeiro, 2004.

ABRELPE - Associação Brasileira de Empresas de Limpeza Pública e Resíduos Especiais. Panorama de Resíduos Sólidos de Resíduos, aprovado pela decisão 94/3/CE de 20 de dezembro de 1993.

\section{Conclusão}

Por meio das informações apresentadas, pode-se concluir que Brasil e Portugal possuem aspectos semelhantes em relação à problemática dos resíduos gerados pela construção. Em ambos os países este setor tem um importante papel na geração de benefícios econômicos e sociais. Entretanto, a construção civil também arca com o ônus dos grandes volumes de resíduos por ela gerados, além da necessidade intensa do consumo de matérias-primas naturais.

É certo comentar que em ambos os países a discussão da problemática em torno dos resíduos de construção e demolição ainda é recente, porém, pode-se afirmar que tanto Portugal como o Brasil já dispõem de mecanismos legislativos e normativos que têm por objetivo regular e fiscalizar a geração de resíduos de construção pelo poder público e estimular a adoção de práticas de redução de geração, reuso e reciclagem destes.

no Brasil. 2012. Disponível em: <http://www.abrelpe.org.br/>. Acesso em: 08 mar. 2013.

Azevedo, G. O.; Kiperstok, A.; Moraes, L. R.Resíduos da construção civil em Salvador: os caminhos para uma gestão sustentável. Engenharia Sanitária e Ambiental, 11(1), 65-72, 2006.

Barros, E.; Jorge, F. C. Gestão de RCD - Resíduos de construção e demolição, na obra de ampliação do aeroporto Francisco Sá Carneiro. Revista da Faculdade de Ciência e Tecnologia, 5, 62-74, 2008.

Brasil. Lei $n^{\circ} 15.445$ de 5 de Janeiro de 2007. Política Nacional de Saneamento Básico. 2. ed. Brasília: Câmara dos Deputados, Edições Câmara, 2012. 73 p.

. Lei $n^{\circ} 12.305$ de 2 de agosto de 2010. Política Nacional de Resíduos Sólidos. 2. ed. Brasília: Câmara dos Deputados, Edições Câmara, 2012. 73 p.

Carneiro, F. P. Diagnóstico e ações da situação atual dos resíduos desconstrução e demolição na cidade do Recife. 
320 p. João Pessoa/PB, Dissertação (Mestrado) - Universidade Federal da Paraíba, 2005.

Coelho, A.; Brito, J. D. Generation of construction and demolition waste in Portugal. Waste Management \& Research , 29(7), 739-750, 2011.

CONAMA - Conselho Nacional do Meio Ambiente. Resolução $n^{\circ} 307$, de 05 de julho de 2002. Estabelece diretrizes, critérios e procedimentos para a gestão dos resíduos da construção civil. Diário Oficial da União, Brasília, DF. Disponível em: <http:// www.mma.gov.br/port/conama/-index.cfm>.

- Conselho Nacional do Meio Ambiente. Resolução $n^{\circ}$ $\overline{348, \text { de }} 16$ de agosto de 2004. Altera a resolução CONAMA n ${ }^{\circ}$ 307 de 5 de julho de 2002, incluindo amianto na classe de resíduos perigosos. Diário Oficial da União, Brasília, DF. Disponível em: <http://www.mma.gov.br/port/conama/-index.cfm>.

- Conselho Nacional do Meio Ambiente. Resolução $\overline{n^{\circ} 431}$, de 25 de maio de 2011. Altera o art. $3^{\circ}$ da Resolução $\mathrm{n}^{\mathrm{o}} 307$, de 5 de julho de 2002, do Conselho Nacional do Meio Ambiente -CONAMA, estabelecendo nova classificação para o gesso. Diário Oficial da União, Brasília, DF. Disponível em: $<$ http://www.mma.gov.br/port/conama/-index.cfm>.

- Conselho Nacional do Meio Ambiente. Resolução

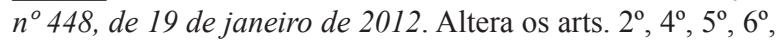
$8^{\circ}, 9^{\circ}, 10$ e 11 da Resolução $n^{\circ} 307$, de 5 de julho de 2002, do Conselho Nacional do Meio Ambiente - CONAMA. Diário Oficial da União, Brasília, DF. Disponível em: <http://www. mma.gov.br/port/conama/-index.cfm>.

Dias, J. A Construção civil e o meio ambiente. In: Anais do Congresso Estadual de Profissionais CREA. Uberlândia, Minas Gerais: CREA MG. 2004.

Diretiva do Parlamento Europeu e do Conselho de 15 de julho de 1975 relativa aos resíduos (Diretiva 75/442/CEE), L194/47. p. 129-131. 1975.

Diretiva do Parlamento Europeu e do Conselho de 19 de novembro de 2008 relativa aos resíduos e que revoga algumas diretivas (Diretiva 2008/98/CE), L312. p. 3-29. 2008.

Diretiva do Parlamento Europeu e do Conselho de 5 de abril 2006 relativa aos resíduos (Diretiva 2006/12/CE), L114. p. 9-21. 2006.

Diretiva do Parlamento Europeu e do Conselho de 12 de dezembro de 1991 relativa aos resíduos perigosos (Diretiva 91/689/CEE), L377. p. 20-27. 1991.

Fonseca, J. J. S. Metodologia da pesquisa cientifica. Fortaleza: UEC, 2002.
Gil, A. C. Como elaborar projetos de pesquisa. 4. ed. São Paulo: Atlas, 2007.

Gomes, C. F.; Nunes, K. R.; Xavier, L. H.; Cardoso, R.; Valle, R. Multicriteria decision making applied to waste recycling in Brazil. Omega , 36(3), 395-404, 2008.

IBGE. Instituto Brasileiro de Geografia e Estatística. Perfil dos Municípios Brasileiros 2011. Disponível em: <http://www. ibge.gov.br>. Acesso em 13/03/2013.

INE. Instituto Nacional de Estatística. Parque Nacional e sua reabilitação. Análise e evolução 2001-2011. 2011. Disponível em: $<$ http://www.ine.pt $>$. Acesso em: 10/03/2013.

John, V. M.; Agopyan, V. Reciclagem de resíduos da construção civil. In: Anais do Seminário - Reciclagem de Resíduos Sólidos Domiciliares. São Paulo: Secretaria de Estado do Meio Ambiente, 2000. 13 p.

Kloek, W.; Blumenthal, K. Generation and treatment of waste. Environmental and energy, Statistic in focus, 30, 2009.

LER - Lista Europeia de Resíduos, União Europeia (03 de março 2004). Portaria n. 209/2004. 25 p.

Lima, T. C. S.; MIOTO, R. C. T. Procedimentos metodológicos na construção do conhecimento científico: a pesquisa bibliográfica. Revista Katalysis, 10, 35-45, 2007.

Mália, M.; Brito, J. D.; Bravo, M. Indicadores de resíduos de construção e demolição para construções residenciais novas. Ambiente Construido, 11(3), 117-130, 2011.

Melo, A.; Gonçalves, A.; Martins, I. Construction and demolition waste generation and management in Lisbon (Portugal). Resources, Conservation and Recycling, 55, 1252-1264, 2011.

Montecinos, W.; Holda, A. Construction and demolition waste management in Denmark. 2006. Disponível em: COWAM $<$ http://cowam.tec-hh.net/Denmark_CD_Waste.pdf $>$. Acesso em: 28/01/2012.

Morais, G. M. D. Diagnóstico da deposição clandestina de resíduos de construção e demolição em bairros periféricos de Uberlândia: subsídios para uma gestão sustentável. 220 p. Uberlândia/MG, Dissertação (Mestrado) - Faculdade de Engenharia Civil, Universidade Federal de Uberlândia, 2006.

Nunes, K. R. R. Avaliação de investimentos e de desempenho de centrais de reciclagem para resíduos de construção civil e demolição: estudo de caso para o município do Rio de Janeiro. 276 p. Rio de Janeiro, Tese (Doutorado) - Universidade Federal do Rio de Janeiro (Faculdade de Engenharia de Produção), Departamento de Engenharia, 2004. 
Pico, F. C. Madeira recuperável em Portugal: estudo do fluxo embalagens de madeira. Lisboa, Dissertação (Mestrado) - Universidade Nova de Lisboa (Faculdade de Ciências e Tecnologia), Departamento de Ciências e Engenharia do Ambiente, 2008.

Portugal. Portaria n 15/96 de 23 de Janeiro de 1996. Diário da República, $1^{\text {a }}$ série (19), 128-129. Portugal: Ministério do Ambiente, do Ordenamento do Território e do Desenvolvimento Regional. 1996.

Decreto Lei $n^{\circ} 239 / 97$ de 9 de setembro de 1997. Diário da República, $1^{\text {a }}$ série (208), 4775-4780. Portugal: Ministério do Ambiente. 1997a.

Portaria $n^{\circ}$ 818/97 de 5 de setembro de 1997. Diário da República, $1^{\mathrm{a}}$ série (205), 4682-4694. Portugal: Ministério do Equipamento, do Planejamento e da Administração do Território. 1997b.

. Portaria $n^{\circ}$ 335/97 de 15 de maio de 1997. Diário da República, $1^{\text {a }}$ série (113), 2440-2441. Portugal: Ministérios da Administração Interna, do Equipamento, do Planejamento e da Administração do Território, da Saúde e do Ambiente. 1997c.

. Portaria $n^{\circ}$ 961/98 de 10 de novembro de 1998. Diário da República, $1^{\text {a }}$ série (260), 6123-6126. Portugal: Ministério do Ambiente, 1998a.

. Portaria $n^{\circ} 792 / 98$ de 22 de setembro de 1998. Diário da República, $1^{\text {a }}$ série (219), 4914-4928. Portugal: Ministério da Economia. 1998b.

. Decreto Lei $n^{\circ} 321 / 99$ de 11 de agosto de 1999. Diário da República, $1^{\mathrm{a}}$ série (186), 5252-5262. Portugal: Ministério do Ambiente. 1999a.

. Decreto Lei $n^{\circ} 516 / 99$ de 2 de agosto de 1999. Diário da República, $1^{\text {a }}$ série (178), 4990-5262. Portugal: Ministério do Ambiente. 1999b.

. Decreto Lei $n^{\circ}$ 152/2002 de 23 de maio de 2002. Diário da República, $1^{\text {a }}$ série (119), 4680-4699. Portugal: Ministério do Ambiente. 2002.

. Portaria $n^{\circ}$ 209/2004 de 3 de março de 2004. Diário da República, $1^{\mathrm{a}}$ série (53), 1188-1206. Portugal: Ministé- rios da Economia, da Agricultura, Desenvolvimento Rural e Pescas, da Saúde e das Cidades, Ordenamento do Território e Ambiente. 2004.

. Portaria $n^{\circ}$ 1408/2006 de 18 de dezembro de 2006.

Diário da República, $1^{\mathrm{a}}$ série, 8474-8475. Portugal: Minitério do Ambiente, do Ordenamento do Território e do Desenvolvimento Regional. 2006a.

Decreto-Lei $n^{\circ} 178$ de 5 de setembro de 2006. Diário da República, $1^{\mathrm{a}}$ série (171), 6526-6545. Portugal: Ministério do Ambiente, do Ordenamento do Território e do Desenvolvimento Regional. 2006b.

. Portaria $n^{\circ} 417 / 2008$ de 11 de junho de 2008. Diário da República, $1^{\mathrm{a}}$ série (111), 3403-3405. Portugal: Ministério do Ambiente, do Ordenamento do Território e do Desenvolvimento Regional. 2008a.

. Decreto-Lei $n^{\circ} 46$ de 12 de março de 2008. Diário da República, $1^{\mathrm{a}}$ série. Portugal: Ministério do Ambiente, do Ordenamento do Território e do Desenvolvimento Regional. 2008b.

. Decreto-Lei 183/2009 de 10 de agosto de 2009. Diário da República, $1^{\mathrm{a}}$ série. Portugal: Ministério do Ambiente, do Ordenamento do Território e do Desenvolvimento Regional. 2009.

Schneider, D. M. Deposições irregulares de resíduos da construção civil na cidade de São Paulo. 82 p. Porto, Dissertação (Mestrado) - Universidade do Porto (Faculdade de Engenharia), Departamento de Engenharia Civil, 2003.

; Philipp Jr., A. Gestão pública de resíduos da construção civil no município de São Paulo. Ambiente Construído, 4(4), 21-32, 2004.

Segorbe, G. J. A. G. Gestão de resíduos de construção, reabilitação e demolição de redes de drenagem de águas residuais. 123 p. Aveiro, Dissertação (Mestrado) - Universidade de Aveiro (Faculdade de Engenharia), Departamento de Engenharia Civil, 2010.

Ulsen, C.; Kahn, H.; Angulo, S. C.; John, V. M. Composição química de agregados mistos de resíduos de construção e demolição do Estado de São Paulo. Revista da Escola de Minas, 63(2), 339-346, 2010. 